\title{
Health risks related to seafood consumption and arsenic speciation in fish and shellfish from North Sea (Southern Bight) and Açu Port area (Brazil)
}

\author{
P. Baisch ${ }^{1}$, Y. Gao ${ }^{2}$, N.V. Larebeke ${ }^{2}$, W. Baeyens ${ }^{2}$, M. Leermakers ${ }^{2}$, N. Mirlean ${ }^{1}$ \& F.M. Júnior ${ }^{3}$ \\ ${ }^{1}$ Laboratório de Oceanografia Geológica, Instituto de Oceanografia, Universidade Federal do Rio Grande (FURG), \\ Rio Grande, RS, Brazil \\ ${ }^{2}$ Analytical, Environmental and Geochemical Department (AMGC), Vrije Universiteit Brussel, Brussels, Belgium \\ ${ }^{3}$ Laboratório de Ensaios Farmacológicos e Toxicológicos, Instituto de Ciências Biológicas, \\ Universidade Federal do Rio Grande (FURG), Rio Grande, RS, Brazil
}

\begin{abstract}
In both the North Sea and the Açu Port (Brazil) coastal areas, high As concentrations were observed in water, soil and sediments. Therefore, the impact of this contamination on fish and shellfish species bought from local fishermen was studied. Total As was assessed by ICP-MS while toxic As was assessed by ICPMS-HPLC and HG-AFS. Several fish species had average Total As concentrations above $1 \mathrm{mg} \mathrm{g}^{-1}$, but the highest concentrations were found in less spotted dogfish, lemon sole and whelks from the North Sea. Toxic As fractions were high in scallops but rarely exceeded $2 \%$ in other species. Considering consumption of $150 \mathrm{~g}$, only 3 samples exceeded the total daily intake. Using mean toxic As concentrations for each species, lifetime cancer risk values at the actual global seafood consumption rate of $54 \mathrm{~g}$ /day are above $10^{-4}$ for whelks, scallops, dogfish, ray and lemon sole.
\end{abstract}

\section{INTRODUCTION}

The North Sea and the Açu Port area (Brazil) ecosystems have been highly impacted by As with sources of different nature. In the North Sea, the average dissolved As concentration is around $0.75 \mathrm{mg} \mathrm{L}^{-1}$, but river input can substantially modify the As baseline.

In the Açu Port area, high As levels in small lakes and marine sediments originate from calcareous biota and iron oxyhydroxides rich in arsenic. Arsenic levels in lake sediments vary between 20 and $270 \mathrm{mg} \mathrm{kg}^{-1}$, while marine sediments contain around $50 \mathrm{mg} \mathrm{kg}^{-1}$ (Mirlean \& Baisch, 2016).

This study aimed at examining if high As levels in both marine ecosystems led to high As levels in fish, at comparing total daily intake of As from fish consumption and at estimating the individual life-time cancer risk due to seafood consumption.

\section{METHODS}

In the North Sea, ray, dogfish, lemon sole, pouting, pollack, brill, cod, whiting and ling (fish species), besides whelks and scallops (shellfish species) were studied. Samples included 79 fish and 37 shellfish. In the Açu Port, located in Brazil's Atlantic coast, big tooth corvina, catfish and shorthead drum $(\mathrm{N}=7)$ were studied. In the North Sea, fish and shellfish were collected in 2009-2010 whereas, in the Açu Port, fish were caught in 2013. Methods used for total As determination in fish comprised microwave assisted mineralization and ICP-MS detection. Arsenic species of fish and shellfish were selectively determined by liquid chromatography-inductively coupled plasma mass spectrometry (ICPMS-HPLC). Separation of As species was performed by an anion exchange column with ammonium phosphate solution as mobile phase. The following arsenic compounds were determined: As(III), As(V), MMA and DMA, which is called toxic As fraction "As-Tox". Arsenic speciation in samples from the North Sea was also determined by hydride generation-atomic fluorescence spectrometry (HG-AFS). All analytical methods comply with quality assurance/quality control procedures.

\section{RESULTS AND DISCUSSION}

\subsection{Arsenic in fish and shellfish}

Species from the North Sea, i.e., pouting, whiting, cod, brill, ling and pollack, seemed to show similar total and toxic arsenic levels in their tissues. Many fish species under study had average concentrations above $1 \mu \mathrm{g} \mathrm{g}^{-1}$, levels which need to be further investigated. Three North Sea species (less spotted dogfish, lemon sole and whelks) were found to be clearly more contaminated than the others. Average Total As levels in thornback ray, pelagic fish group and scallops (North Sea species) and tilefish, namorado sandperch and pink conger (Rio de Janeiro coastal fish species) ranged from 1 to $13 \mu \mathrm{gg}^{-1}$. It indicates that, for several fish species, comparable levels were observed in both marine areas. However, additional studies of As speciation in fish are critical for the assessment of consumption risk because arsenobetaine, a non-toxic form, is the major As species in marine fish. In the 
Açu Port area (RJ-Brazil), average total arsenic concentrations in drum, catfish and corvina fish species ranged from 0.73 to $8.9 \mu \mathrm{gg}^{-1}$. Average toxic arsenic levels are high in less spotted dogfish, whelk, scallop and lemon sole (from 0.15 to $0.46 \mu \mathrm{g} \mathrm{g}^{-1}$ ) while in bigtooth corvina, catfish, pelagic fish group and shorthead drum, levels ranged between 0.023 and 0.067 $\mu \mathrm{g} \mathrm{g}^{-1}$. In fish, the highest arsenic (total and toxic) levels were found in dogfish and lemon sole, both from the North Sea, but dogfish was also the longest $(632 \mathrm{~mm})$ fish species under study. Correlations between toxic and total As levels in fish muscle were generally good with a correlation coefficient $r$ equal to 0.78 for all fish species and 0.75 for whelks. Correlation was not good $(\mathrm{r}=0.33)$ for scallops, only. The highest toxic arsenic fractions (toxic arsenic conc./total arsenic conc.) were found in great scallops $(8.9 \%)$ and bigtooth corvina (3.2\%), whereas the lowest ones were found in less spotted dogfish $(0.6 \%)$ and lemon sole $(0.7 \%)$. Data showed that toxic arsenic fractions in fish and shellfish were small by comparison with those found in surrounding water and sediment.

\subsection{Cancer risk assessment}

Cancer risk assessments were expressed as Individual lifetime cancer risk (TR). This assessment is defined as the daily average intake per kg of body weight, multiplied by an element-specific factor, the so-called slope factor (SF). TR can be calculated by:

$\mathrm{TR}=\frac{\mathrm{CR} * \mathrm{Cf} * \mathrm{EF} * \mathrm{ED} * \mathrm{SF}}{\mathrm{BW} * \mathrm{AT}}$

where $\mathrm{CR}$ is consumption rate of seafood, $\mathrm{CF}$ is the 95th upper confidence limit of the toxic as concentration mean for all samples, EF is the exposure frequency, ED is exposure time, BW is body weight and AT is averaging time. In the case of cancer effects, consumption of $13.5 \mathrm{~g} \mathrm{day}^{-1}$ seafood with an average toxic As concentration shows, only for whelks and lemon sole individual lifetime cancer risks that are higher than the acceptable limit. Those seafood species were also the ones that exceeded the permissible dose calculation (Table 1). However, fish consumption in the world increased from 13.5 (USEPA,1997) to $54 \mathrm{~g} \mathrm{day}^{-1}$ (FAO, 2016) in 20 years. Considering seafood consumption of $54 \mathrm{~g}_{\text {day }}{ }^{-1}$, whelks, scallops, dogfish, ray and lemon sole exceeded the acceptable limit in case average toxic As values are used; Besides, the pelagic fish group joins those species when the 95th percentile of the toxic arsenic levels is used. In addition, when estimating cancer risks, one should take into account that arsenic is only one of the multiple carcinogens to which humans are exposed to. The fact that seafood essentially contains arsenobetaine, a nontoxic arsenic form, is a reassuring element. But the presence of arsenic in seafood, which is similar to inorganic As in terms of metabolite formation and tissue accumulation, should be considered. In addition, after seafood storage and cooking, toxic arsenic metabolites can be formed.
Table 1. Lifetime cancer risks of consumption of seafood species for 2 consumption rates ( $13.5 \mathrm{~g}$ day $1 \mathrm{TR} 2$ and $54 \mathrm{~g}$ day 1 TR1) and 2 concentrations (mean and 95th percentile). Consumption As-Tox concentration 95th upper confidence limit (1); 95th percentile (2).

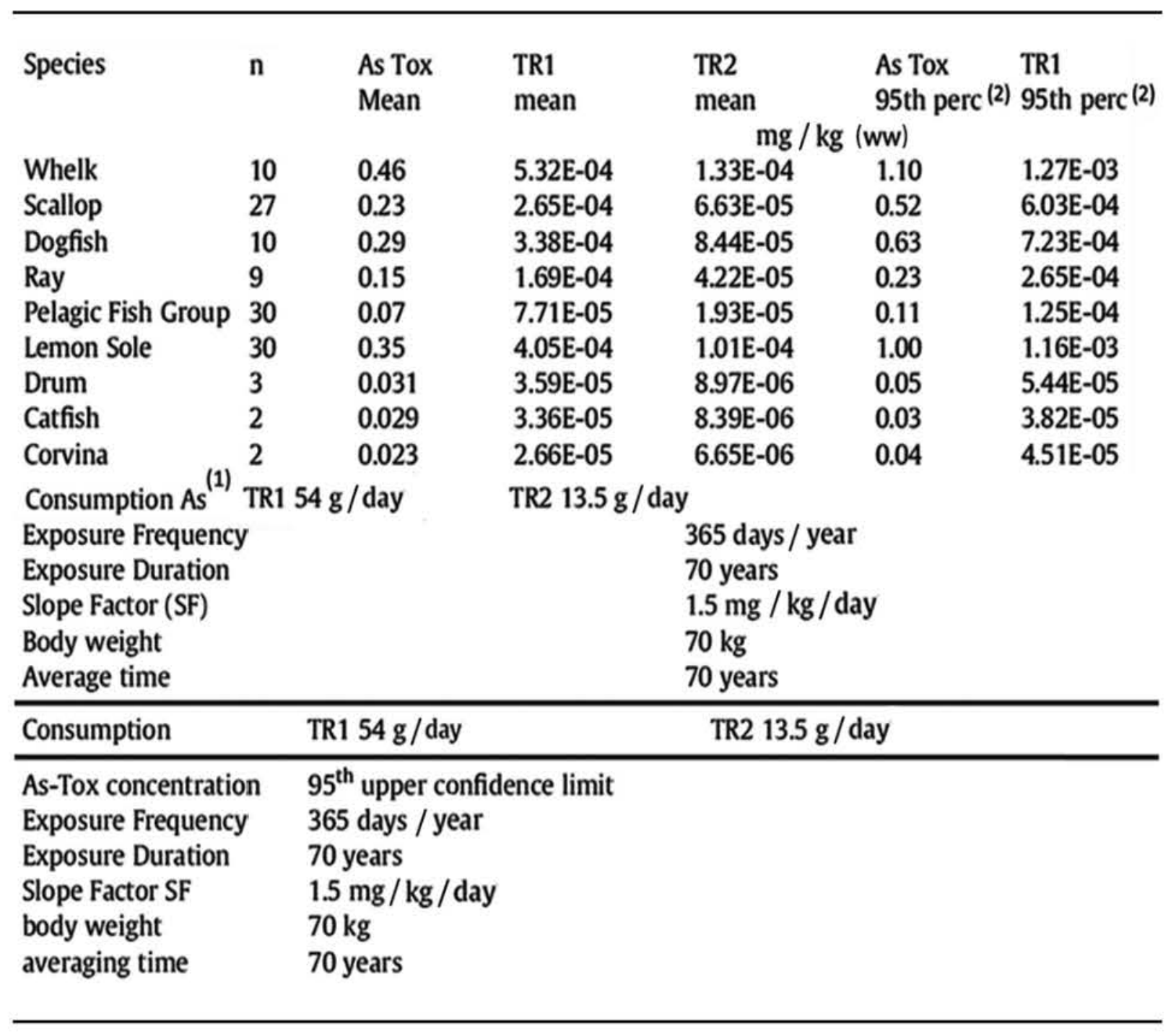

\section{CONCLUSIONS}

Several fish species had average total As concentrations above $1 \mu \mathrm{g} \mathrm{g}^{-1}$ wet weight, but the highest levels, i. e., 50,49 and $50 \mu \mathrm{gg}^{-1}$, were found in less spotted dogfish, lemon sole and whelks from the North Sea, respectively. High Total As levels correspond to high toxic As levels, except for scallops having increased toxic As concentrations. toxic As fractions were high in scallops $(10 \%)$ but rarely exceeded $2 \%$ in the other species. Toxic arsenic fractions in liver samples were 2-4-fold higher than the ones in muscle. Considering consumption of $150 \mathrm{~g}$ seafood, only 3 samples exceeded the provisional total daily intake of $2 \mathrm{mg} \mathrm{As} \mathrm{kg}^{-1}$. However, cancer risks are nonnegligible. Using mean toxic As concentrations for each of the different fish and shellfish species under study, lifetime cancer risk values at the actual global seafood consumption rate of $54 \mathrm{~g}_{\text {day }}{ }^{-1}$ were above $10^{-4}$ for whelks, scallops, dogfish, ray and lemon sole.

\section{ACKNOWLEDGEMENTS}

The authors thank the CB\&I Company for the support in the field work in the Açu Port area.

\section{REFERENCES}

FAO, 2016. The State of World Fisheries and Aquaculture, p. 204.

Mirlean, N. \& Baisch, P. 2016. Arsenic in Brazilian tropical coastal zone. Proceedings $6^{\circ}$ Intern. Congress on Arsenic in the Environment. CRC Press, Boca Raton, FL, pp. 169-170.

USEPA. 1997. Exposure Factors Handbook. Update to Exposure Factors Handbook (Chapter 10): Intake of fish and shellfish. EPA/600/8e89/043. 